\title{
The Image of India in Hong Ying Literature
}

\author{
Ting Ye \\ College of Liberal Arts \\ Jinan University \\ Guangzhou, China
}

\begin{abstract}
With the advent of globalization, transnational writing has become an important feature of authors' creation. The investigation of the foreign country image in the writer's works is helpful for finding many significant deep-seated factors. Hongying is a well-known overseas Chinese writer. Many elements about India can be found in her works, especially in the novel Out of India. In Hongying's masterpieces, India at the end of the 20th century, with backward material civilization but ancient and long spiritual civilization, can still be called a holy land. The biggest characteristic of India is that it is a Buddhist country. The invasion of Buddhism can not only purify the men and women who lost their way in the crossflow of material desires, but also restore the tranquility of the soul to the people who are trapped by the love. The image of India in Hongying's works is not only related to the historical context of China and India, but also to her personal understanding of India.
\end{abstract}

Keywords—Hong Ying; India; Buddhist country

\section{INTRODUCTION}

Hongying is a powerful overseas Chinese writer. She rose to the literary world by writing poems and later, she won a place by novels. Her autobiographical novel Daughter of the River was highly praised. As a writer, Hongying is famous for her wild rebellion. Her masterpiece Out of India has also attracted the attention of many readers. Hongying once went to India and then, turned into an eminent India-based writer. Out of India is a novel specially descripting India. India is indeed worth exploring. On the one hand, India is neighboring to China and one of the four ancient civilizations with the same China. On the other hand, modern India is strange to the rest of world, which is quite intriguing.

\section{THE IMAGE OF INDIA}

In order to attract readers, the writer tends to describe strange scenery or customs when he/she travels to a country to strengthen the image of "the other". So does Hongying. India in Hongying's works is an exotic "the other". The exotic atmosphere in the novel means a stress of the difference on "the other". To emphasize the fracture of space, it is necessary for travelers to move from native country to foreign land.

India has not only beautiful natural scenery, but also unique attraction for its unique geographical location and landform. The Taj Mahal in India is a famous tourist attraction around the world. Because Taj Mahal is a symbol of sacred love, to visit it means to express admiration for the ideal love. In addition to the exotic nature of the landscape, various cultural customs also show the characteristics of the foreignness, causing readers infinite reverie. Besides that, Indian food is so delicious. For one of the world's super delicious Indian dishes, $35 \%$ of the enjoyment of them comes from smell, $35 \%$ from taste, and the rest $30 \%$ from vision, hearing and touch. Moreover, Indian architecture is unique. Indian buildings are more likely than any other authority to make people feel who the city belongs to. Indian art is amazing. Indian music and dance are well-known globally. Su Fei said that Indian dance plays are greatly colorful: Gods are also to do stupid things due to jealousy. And Indian music is close to the realm of meditation, so that it will get one person possessed if he/she listening for a long time. ${ }^{1}$

India's modernization lies in its affluence. "The world I am going to is outside the hotel. The streets nearby are clean and shady. The skyscrapers with the glass walls are magnificent and glamorous. Just like any big city in the world, the modernization here is shiny and brightly displayed." What's more, the Internet of India is developed." 2The network speed here is faster than that in Beijing, and the Internet in India is advanced and all-pervading, which intrigues my admiration. There are so many Internet cafes. It can be seen that here more people will go to Internet cafes than in China. Ordinary Indians don't have the money to buy computers and make phone calls, but luckily, it's cheap and easy to go to Internet cafes, which is probably marvelous for any other country."3

India shows a strong sense of history. When one stepping into the old town of Delhi, it seems that he has come to a place with its own history: a strong vitality burst out majestically. In Hongying's novels, all references to ancient Indian civilization are full of admiration.

The Ganges River is beautiful and sacred. Coming from the nature, the river cleans away the dirt and makes the world pristine. The river is also the junction of the fairyland and the mortal world as well as interconnection channel between human beings and gods. The combination of the flow characteristics of the river and the cleaning effect gradually evolved into the baptism function of the soul under the stimulation of mystery. The sanctity of India also derives from the fact that India is a religious country. India's religions are so

Hongying: Out of India, Nanjing: Jiangsu literature and Art Publishing House, 2013, page 96.

Hongying: Out of India, Nanjing: Jiangsu literature and Art Publishing House, 2013, page 19.

Hongying: Out of India, Nanjing: Jiangsu literature and Art Publishing House, 2013, page 72 
diverse that almost everyone believes in religion. So, Indian's life has extraordinary spiritual significance.

In India, at the end of the 20th century, the exotic touch Hongying experienced was not merely featured by romance. India is a country of distinct classes and a strong sense of hierarchy. There, the trains are classified into first-rate, ordinary and second class, and the first class is further split into five categories based on the advantages and disadvantages. Hongying said emotionally: "it's really a hierarchical nation! I'm confused and furious." 4 India's caste system is an important feature of ancient Indian society, which even has persisted to this day. Repeatedly, the harm of hierarchy represented by caste system was attacked by Hongying. India is dirty. The garbage is piled up into hills and stinks. The filth of the street is really stinky and unpalatable. The folk custom is no longer simple. "The thief may be walking through the crowd, just around me." India is poor. Although some places in India are very rich, which can be compared with the advanced places in the world, such as high-end hotels, more places are pretty poverty-stricken. "Going north to the Connaught Ring Road, I found that it's so messy. Here, a real India revealed itself." 6 This shows the sharp differences in living conditions. It is the most vivid comparison between the backward and the advanced civilizations. And it is a view of India from the perspective of Hong Kong and Beijing.

When the writer came to India, the power relationship between her and the place where she traveled was unfolded, that is, he despised India in reality. "I'm not a racist. If I have to choose one person to live together, it will be ok for other nationalities just because of affection. However, I just don't want to live with an Indian, no matter how beautiful she is. Maybe the reason I don't know is the deepest reason in the subconscious. Maybe in the subconscious, the Chinese look down on the Indians the most, and the Indians also look down on the Chinese the most.",

\section{THE SALVATION OF INDIA'S BUdDHISTS FOR THOSE WHO HAVE LOST THEIR WAY IN MATERIAL LIFE}

The plot of the novel is meaningful. I have a transformation process from worshiping Anan to accepting his hideous side. The novel originates from the love for Anan, who is the first rock star of different genres and the right image that I worshipped fifteen or six years ago. But I never got to know this strange man. I've heard so much about this man since I met Su Fei and became good friends with her.

The name, Anan, embraces diverse meanings. It is a name in the Sutra and it is a Sanskrit translation of Ananda. Ananda is the ninth disciple of Sakyamuni in Buddhism. He is handsome, young and very clever. But he encountered great magic, and almost lost his attainments in the face of the

\footnotetext{
Hongying: Out of India, Nanjing: Jiangsu literature and Art Publishing House, 2013, page 56.

Hongying: Out of India, Nanjing: Jiangsu literature and Art Publishing House, 2013, page 22.

6 Hongying: Out of India, Nanjing: Jiangsu literature and Art Publishing House, 2013, page 19.

Hongying: Out of India, Nanjing: Jiangsu literature and Art Publishing House, 2013, page 35.
}

temptation of the modern woman. When he saw the Tathagata, he saluted the Buddha's feet and regretted himself. Although he didn't get the complete attainments, he got the most sutras from the Tathagata. He was famous for his "multiple knowledge" and gained the supreme wisdom. This is a process from temptation to redemption. This name seems to be enough to explain all the characteristics of Anan and also enough to indicate his experience.

Anan (Huang Yalian), in Hongying's opus, is a mysterious but attractive singer, whose music is very pleasant. "If Oriental people can have their own rock music, I think Anan opens up a unique way. Along this way, Anan is even qualified to give

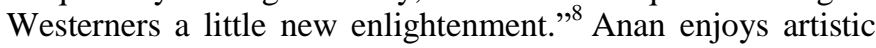
pursuit and taste. His taste has reached a level of high grade. Even if he becomes a businessman someday, his home furnishings will all reflect a certain taste, and there is no vulgarity of upstarts.

Unfortunately, the idol that Su Fei and I adore is a criminal of the blackest dye, a bureaucrat and profiteer who bring suffering to the people. Hong Kong media has been saying that Anan and Su Fei, together with a number of Southeast Asian family consortiums, have committed heinous crimes. As a businessman, Anan has no faith or conscience. As a man of semi Indian origin, Anan wanders alongside the route coinciding with that of Sakyamuni and his disciple Ananda's preaching along the Ganges River and Xuanzang's traveling. But at this time, although Anan was wandering, he had no faith Anan (Huang Yalian) said, "we do anything except for those about weapons and human trafficking. No one can stand the test of money, lust and flattery." Meng Hao is determined to expose Huang Yalian's mask of pretending to be a Confucian businessman! In the materialistic society, Anan also suffered temptation. The dilemma between material pursuit and spiritual pursuit can also be interpreted to be the dilemma between reality and ideal, body and soul, which is the biggest dilemma that Anan encounters.

In the novel, Hongying tries to put forward the theme of $\sin$ and redemption: the sin of Anan and the sin of social history. Ananda is indeed a sinner, but he is not a man without spiritual pursuit. It is hard to say that he is a villain with evil nature. Anan's life experience reminds people of the elites. He is brilliant, but he is just the product of the times. It is inevitable for Anan to become Huang Yalian, which has a lot to do with institutional corruption. Most people in the society can't escape corruption. As an artist, Anan may feel more satisfied with money than others.

Ananda's criminal partner and lover is $\mathrm{Su} F e i$, executive deputy editor of Hong Kong Daily, CEO of xingyun.com and chairman of Tuteng Film and Television Company. The woman is regarded as the top media figure in Hong Kong and a famous able woman of new economy. Su Fei is very elegant. Unlike those upstart rich women of so many property values as Meng Hao said, Su Fei never finds out how to lavish money to

Hongying: Out of India, Nanjing: Jiangsu literature and Art Publishing House, 2013, page 29.

Hongying: Out of India, Nanjing: Jiangsu literature and Art Publishing House, 2013, page 156. 
show off her wealth. Although she presides over several companies and many subordinates follow her will, she is not domineering at all.

However, Anan and Su Fei both embarked on the road of grabbing money crazily. Although Anan and Su Fei are really in love, they have clear interest exchanges. In addition, Su Fei's greed for money makes Anan hate that he has the same weakness. What's more, Su Fei is the daughter of Anan's father murderer and enemy, which makes their fragile love worse and makes the increasingly estranged affection turn to be nothing. So, both of them choose to die. It is not only people who are brave and unfortunate that want to die, but also those who are tired of life.

Anan and Su Fei wash their sins in the Ganges. Hongying wants to get rid of the sin with the help of religion in her works. Only when there is "sin", can redemption be needed. Anan and $\mathrm{Su}$ Fei in out of India are trapped in the whirlpool of sin. The unbelievers have no way to get rid of sin, so they can only walk into the cold Ganges in the morning. The Ganges in India shows compassion and the death of Anan and Su Fei is nirvana.

\section{INDiA'S Buddhist CURES Those WhO ARE TRAPPED IN LOVE}

"I" am a very important character in this novel. The exotic image of "the other" is mainly produced in the interaction between "I" (the narrator or the watcher) and "the other" (the narrator and the one being watched), and exists for the purpose of speaking about "me". "I" am a writer and "I" work hard. Meng Hao said that he urgently needed a female writer, who had a deep relationship with the Hong Kong Publishing Industry and knew about $\mathrm{Su}$ Fei from the beginning, so that she would not be doubted. At the same time, it is crucial for her to be relatively reliable, which means that she won't be lost in money and dragged into the mire by the millionaire's lifestyle. He added that years of observation have proved that "I" have these qualities. "My" career is at a low ebb and the writing is also encountering a bottleneck period. Under this circumstance, it's not that "I" can't make up a story, it's that "I" can't satisfy myself

Buddhism makes me understand that life is hard and I should be used to it. However, the concept of "bitter essence" in Buddhism is a kind of interpretation of life value based on a serious understanding of the real-life predicament, full of noble life feelings and concerns.

Suffering from the separation: I feel painful for the death of my loving father and I miss him deeply. I did not know my father loves me so much until he died. When I knew how to love him, he was not alive. My father gave me the most perfect love, but such a father has passed away, leaving me with permanent pain and missing. In my works, I exist as a just writer and investigator, and $\mathrm{I}$ am also in emotional entanglement with my husband, whose unfaithfulness brings me great pain. I have a husband who is a biology professor in University. He and I are not like husband and wife. Instead, we just keep a seemingly peaceful family. Without me, his life is

10 Hongying: Out of India, Nanjing: Jiangsu literature and Art Publishing House, 2013, page 152. more wonderful; without him, I still live. My husband keeps looking for women and making love to other women in front of me. Every time I think about this, my sadness will be beyond my expression. This is pain of asking but no answering. This is love pain. Of all our feelings, love and jealousy are the most bewildering and fascinating. This strong desire often leads us into confusion of imagination. The lust world is considered to be short-lived, bitter and illusory.

I couldn't bear the pain. So, I went to India. Although India is not a pure land, India is a Buddhist country. It taught me enlightenment and purification. In the world of filth, life is bitter, including suffering from old age and illness, asking but no answering, complaining and hating, loving but departing and five shengyin. Unlike earthly world, pure land is a clean place or a solemn world. It is a fresh world free from pollution and filth, a good society and a beautiful world. Compared with the filthy land of the world, the pure land of Buddhism expresses people's disgust to the real world and their yearning for a better world in the future.

I have come back to China from India as a man of understanding. Free from the confused mind, my husband is willing to break off the relationship with other women and continue life with me. I'm a woman of easiness to compromise. It turns out that opening your eyes is better than closing them to be void. The uneasiness and perplexity in life may be encountered by everyone and the efforts to eliminate the perplexity may vary greatly. It is a normal idea to hope to get rid of the perplexity in life. To achieving this aim, it is a good way to convert to religion. Belief is the last spiritual conversion that Hong Ying thinks. This spiritual conversion must be holy, perfect, constant and true.

\section{COLLECTIVE IMAGINATION AND HONGYING'S CONCEPT OF INDIA}

Hongying's impressions of India all come from what she saw and felt in India, which is reasonable. However, Hongying was a tourist when she went to India. Therefore, the alien image in the travel writing is not simply a copy of reality, but more integrated into the imaginative description of the writer's emotion and value, which is the projection of the writer's social collective cultural imagination.

India is never new to China and is full of strong attraction. According to Xuanzang's Buddhist Records of the Western World, in the eyes of Chinese people, India is a country full of mystery, legend, exotic customs and ancient civilization.

India has a long history. As a close neighbor of China, India has a splendid civilization of five thousand years and it is one of the oldest civilized countries in the world. Among the four major civilizations in the ancient world, Egyptian civilization and Mesopotamian civilization suffered disconnection in the process of development, while Chinese and Indian civilizations have been in succession since ancient times. India seems to be covered with a mysterious veil.

India is a religious country. In India, almost all people have religion belief. It is still the introduction of Buddhism that makes Chinese people full of gratitude and yearning for Indian culture. For Chinese, Buddhism belongs to China, but after all, 
it comes from India. India's most eye-catching places of interest are religious buildings, the most bustling and bustling places are temples, and the most exquisite handicrafts are sacrificial products of gods. In India, religion is not only a belief, but also a way of life and a national identity. There are many sects in India and they enjoy devout faith of believers.

Indians have strong cultural confidence. Indian civilization is subject to Oriental civilization. India attaches great importance to people's spiritual life and is indifferent to material life.

The caste system in Indian culture is very strict. India's caste system divides people into four different classes: Brahman, Kshatriya, Veda and Sudra. Brahmin is a monk who belongs to the first caste with the highest status, engaged in cultural education and sacrifice; Kshatriya is a warrior, Prince, aristocrat, etc. who belongs to the second caste, engaged in administrative management and war; Vaisya is a businessman who belongs to the third caste, engaged in commercial trade; Sudra is a farmer who belongs to the fourth caste with the lowest status, engaged in agriculture and various physical and handicraft labor, etc. Castes are hereditary. For thousands of years, the caste system has had a profound impact on people's daily life and customs. The caste discrimination has not been eliminated so far, and the situation in rural areas is even more serious.

India was once a British colony, and British colonial exploitation is the root cause of India's poverty and economic backwardness. India is rising today, and India's economic reform has achieved remarkable results, but there are still many problems, especially social inequality, rural poverty, overpopulation and environmental damage. As a discourse, the image of a foreign country not only produces but also reflects its social context.

China is also becoming stronger. From the perspective of the background of international relations, in the 1970s, China's position and influence in the world has been continuously enhanced. Hong Kong is developed and bustling. Before Hong Kong's return in 1997, it was under British rule for a century and a half, which makes it a land closely connected with the western world and became a highly liberalized, legalized and commercialized society. It can be said that Hong Kong was a "western" Chinese society. After more than 100 years of development, Hong Kong has made remarkable economic achievements in the second half of the 20th century, becoming one of the "four little dragons" in Asia, thus stepping into the ranks of the world's developed society. "Since the 1960s, especially since China adopted the reform and opening up policy, Hong Kong's economy has grown rapidly and created a remarkable economic miracle." 11 There are many beautiful emblems in Hong Kong - the Pearl of the East, the jewels on the crown of the Empire, the windows of democracy, the paradise on earth, the wonderland of smugglers. These emblems show the prosperity of Hong Kong. Lamma Island in Hong Kong is the place where Su Fei and Anan live happily. Lamma Island is also named as Boliaozhou, which is the third

11 Liu Shuyong: A Brief History of Hongkong, Beijing: Social Science Academic Press, 2011, page 78. largest island in Hong Kong except Lantau Island and Hong Kong island. Because Hong Kong is located in the subtropical zone, the flowers and trees on the island are luxuriant, and the natural scenery is wonderful. But developed China has no faith In the 20th century, the Chinese people who have embarked on the road of modernization are in a vacuum of belief.

The Indian experience influences Hongying's creation. Hongying's trip to India is not considered as the true and objective representation of the whole nation, but a filtered production consciously or unconsciously influenced by the author's own identity and values. Hongying was influenced by Buddhism before going to India, during his trip in India and after returning home from India. The fact that Hongying was affected by Buddhism undoubtedly influenced the story of Out of India.

Hongying's primary understanding of India influences how she will shape India. The "I" in the novel can also be said to be the writer's understanding of India by reading the most famous Chinese texts written about India: Historical Records and Journey to the West. There is a frightening name in the Historical Records, which is called "sindhu". If you want to visit India, you can't just go with spirit. It's advisable for you to be equipped with the tenacity and perseverance to pursue. After all, that's where Xuanzang went. ${ }^{12}$ About 1500 years ago, master Xuanzang traveled through mountains and rivers to India. Hong Ying has always had an interest in ancient India.

Hongying's experience in India has played a great role. She thinks that she has toured many famous cities in her time in India. From her narration, it can be seen that Hongying has her own understanding of the local Indian society and no longer repeat what others say. Cross cultural experience and cognition will be produced in the process of crossing borders, which is not only valuable experience for the writer, but also has a positive effect on promoting social exchanges and cultural undertakings in two or more places.

\section{CONCLUSION}

In Hongying's literary works, although contemporary India is backward, its economy is no longer prosperous, and it is no longer clean and tidy, after all, India is an ancient civilization with a long history, and its charm of history and culture is still beckoning. As the land of Buddhism, India is the best place to redeem sins. Buddhism also helps people suffering from love pain to have a better understanding of life. As a Buddhist country, India's sanctity is beyond doubt.

\section{REFERENCES}

[1] Hongying: Out of India, Nanjing: Jiangsu literature and Art Publishing House, 2013, page 96. (in Chinese)

[2] Hongying: Out of India, Nanjing: Jiangsu literature and Art Publishing House, 2013, page 19. (in Chinese)

[3] Hongying: Out of India, Nanjing: Jiangsu literature and Art Publishing House, 2013, page 72. (in Chinese)

12 Hongying: Out of India, Nanjing: Jiangsu literature and Art Publishing House, 2013, page 11. 
[4] Hongying: Out of India, Nanjing: Jiangsu literature and Art Publishing House, 2013, page 56. (in Chinese)

[5] Hongying: Out of India, Nanjing: Jiangsu literature and Art Publishing House, 2013, page 22. (in Chinese)

[6] Hongying: Out of India, Nanjing: Jiangsu literature and Art Publishing House, 2013, page 19. (in Chinese)

[7] Hongying: Out of India, Nanjing: Jiangsu literature and Art Publishing House, 2013, page 35. (in Chinese)

[8] Hongying: Out of India, Nanjing: Jiangsu literature and Art Publishing House, 2013, page 29. (in Chinese)

[9] Hongying: Out of India, Nanjing: Jiangsu literature and Art Publishing House, 2013, page 156. (in Chinese)

[10] Hongying: Out of India, Nanjing: Jiangsu literature and Art Publishing House, 2013, page 152. (in Chinese)

[11] Liu Shuyong: A Brief History of Hongkong, Beijing: Social Science Academic Press, 2011, page 78. (in Chinese)

[12] Hongying: Out of India, Nanjing: Jiangsu literature and Art Publishing House, 2013, page 11. (in Chinese) 